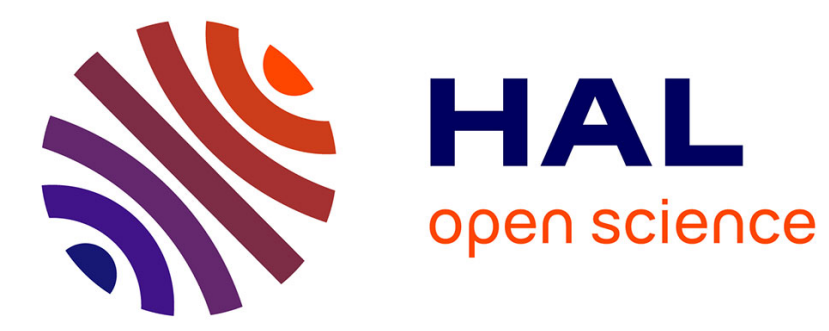

\title{
Impacts of payments for environmental services on local development in northern Costa Rica: A fuzzy multi-criteria analysis
}

Bruno Locatelli, Varinia Rojas, Zenia Salinas

\section{- To cite this version:}

Bruno Locatelli, Varinia Rojas, Zenia Salinas. Impacts of payments for environmental services on local development in northern Costa Rica: A fuzzy multi-criteria analysis. Forest Policy and Economics, 2008, 10 (5), pp.275-285. 10.1016/j.forpol.2007.11.007 • cirad-00699330

\section{HAL Id: cirad-00699330 \\ http://hal.cirad.fr/cirad-00699330}

Submitted on 20 May 2012

HAL is a multi-disciplinary open access archive for the deposit and dissemination of scientific research documents, whether they are published or not. The documents may come from teaching and research institutions in France or abroad, or from public or private research centers.
L'archive ouverte pluridisciplinaire $\mathbf{H A L}$, est destinée au dépôt et à la diffusion de documents scientifiques de niveau recherche, publiés ou non, émanant des établissements d'enseignement et de recherche français ou étrangers, des laboratoires publics ou privés. 


\title{
I mpacts of payments for environmental services on local development in northern Costa Rica: A fuzzy multi-criteria analysis
}

\author{
Bruno Locatelli (1,2), Varinia Rojas (3), Zenia Salinas (2) \\ 1: CIRAD UPR Forest Resources, Montpellier 34398, France \\ 2: CATIE, Global Change Group, Turrialba 7170, Costa Rica \\ 3: ACICAFOC (Asociación Coordinadora Indígena y Campesina de Agroforestería Comunitaria Centroaméricana), \\ Apdo 2089-1002, San José, Costa Rica
}

Accepted version of the following paper:

Locatelli B., Rojas V., Salinas Z., 2008. Impacts of payments for environmental services on local development in northern Costa Rica: A fuzzy multi-criteria analysis. Forest Policy and Economics 10: 275-285.

\begin{abstract}
Market mechanisms for forest environmental services are increasingly used for promoting environmental conservation, and their impacts on development are of considerable interest. In Costa Rica a national scheme of Payment for Environmental Services (PSA) rewards landowners for the services provided by different forest land-uses. We evaluated the impacts of reforestation under the PSA on local development in the North of the country. We applied a fuzzy multi-criteria analysis including socioeconomic, institutional, and cultural dimensions and based on the individual perceptions of landowners. The impacts of the PSA applied to reforestation are positive; negative economic impacts are balanced by positive institutional and cultural impacts. In most dimensions, the impacts on the poorest landowners are notably positive and generally higher than for upper class landowners. However, the short-term incomes of the poorest landowners decrease as a consequence of reforestation. This problem may engender negative outcomes and reduce the participation of the poorest landowners in the PSA. Positive impacts were stronger for landowners applying to the PSA through a local nongovernmental organization.
\end{abstract}

\section{Keywords}

Payments for environmental services; Forest; Plantation; Local development; Costa Rica 


\section{I ntroduction}

Forest ecosystems provide a wide variety of environmental services such as water regulation, biodiversity conservation, or carbon storage for climate change mitigation (de Groot et al., 2002). Market mechanisms for forest environmental services are increasingly being used for promoting environmental conservation and their impacts on development are of considerable interest (Grieg-Gran et al., 2005). Implementing payment for environmental services (PES) mechanisms can be a way to achieve development goals and natural resource conservation, especially in low-income regions (Tschakert, 2007). In Costa Rica, a national scheme of Payment for Environmental Services, called PSA ${ }^{1}$ or "Pago por Servicios Ambientales", was created in 1997 (Chomitz et al., 1999) that rewards environmental services provided by different land-uses or forest activities, such as forest conservation, reforestation, and agroforestry.

PES for reforestation, or more generally the financial incentives for reforestation, have been widely criticized for their possible negative impacts on local development and environment (Bull et al., 2006). This debate has been recently reactivated by the inclusion of afforestation and reforestation projects under the Clean Development Mechanism (CDM) of the Kyoto Protocol (Totten et al., 2003). As for PES, payments for carbon under the CDM may contribute to rural development but may also create social tensions or have negative impacts on livelihoods (Perez et al., 2007; Smith and Scherr, 2003).

The PSA in Costa Rica was created primarily for environmental purposes; however, secondary objectives include income generation and employment opportunities for rural populations, thereby justifying our study on the impacts of PSA on local development. In addition, development returns for PSA are important because funding comes from the national budget, international development agencies, and buyers of environmental services who see social benefits as the most important criterion of forestry projects (Sell et al., 2006).

Research has been conducted on the links between poverty and PES. According to Grieg-Gran et al. (2005), three key questions are evaluated: (1) the ability of smallholders to sell environmental services relative to better-off stakeholders, (2) the effect of PES on the livelihoods of the poor directly involved in PES and, (3) the effect of PES on the livelihoods of other poor persons not directly involved in PES. For the second and third questions, Vogel (2002) applied a methodology based on a critique of the Sustainable Livelihoods Approach in Ecuador, and Rosales (2003) studied the institutional process of PES as well as the social and economic impacts (e.g. employment, income, migration, or culture) in the Philippines. In Costa Rica,

\footnotetext{
${ }^{1}$ In this paper, PES is used as general term and PSA refers to the Costa Rican PES.
} 
various empirical field studies dealt with the environmental and social impacts of the PSA (Rojas and Aylward, 2003) and landowner participation (Zbinden and Lee, 2005). Studies have been conducted in Central and Northern Costa Rica, utilizing focal groups (Miranda et al., 2004) or individual interviews (Miranda et al., 2003) for collection of primary information.

Some studies are biased because "benefits are widely applauded, and costs are poorly recorded" (Grieg-Gran and Bann, 2003). Moreover, in some studies, the impacts of PES are not clearly distinguished from the business-as-usual course, as changes are not necessarily a consequence of the PES. In some studies dealing with the participation of smallholders, the prevailing assumption is that their participation should be increased because of the PES positive impact.

This paper evaluates the impacts of reforestation under the PSA on local development in northern Costa Rica. We focused on the perception of impacts by landowners or key persons and on the diversity of landowners. We did not consider reasons for participation. This paper will show that (1) the overall impact of the PSA is positive; (2) negative economic impacts are balanced by positive institutional and cultural impacts; (3) both positive and negative impacts are stronger for poor landowners than better-off landowners; and (4) the support of local organizations improves the impact of the PSA. The hypotheses were evaluated through the application of a multi-criteria analysis with fuzzy set theory.

\section{Materials}

In 1997, Costa Rica established a national scheme of Payment for Environmental Services (PSA). Landowners can voluntarily apply to the PSA and receive payment proportional to the area dedicated to forest conservation and reforestation. Forest management had been an eligible activity until 2002, and agroforestry has been eligible since 2003. The PSA considers four environmental services: hydrological services, scenic beauty, carbon sequestration, and biodiversity protection (Chomitz et al., 1999). During our fieldwork in 2004, the PSA paid US $\$ 550$ per reforested hectare during the first 5 years ( $50 \%$ in the first year, then $20 \%, 15 \%, 10 \%$, and $5 \%$ in years 2 to 5). In 2005, Fonafifo decided to increase the total payment and the initial payment for inversion, as well as the duration of the payment to 10 years. Since 2006, one reforested hectare has been paid US\$ 816 (46\% during the first year and $6 \%$ yearly in the subsequent 9 years). Under both payment schemes, landowners must undertake to conserve the reforestation during at least 15 years (Fonafifo, 2006). In comparison, forest conservation has been paid a total of US\$ 64, evenly distributed during 5 years. Between 1997 and 2005, 89\% of areas under PSA were dedicated to forest conservation. Reforestation reached 27,000 ha during the same period, representing a reforestation rate of 3000 ha/year. 
Distinct institutions participate in the implementation of the PSA. The most important public institution is Fonafifo (Fondo Nacional de Financiamiento Forestal). At the national level, Fonafifo collects and manages funds received from a specific tax on fuel and from additional sources, such as carbon credits trade, international donors, local hydroelectric and agribusiness interested in hydrological services, and ecotourism business interested in scenic beauty (Rojas and Aylward, 2003). Landowners can apply to the PSA at the regional Fonafifo offices. Applicants must present administrative and legal documents, as well as a technical study conducted by a forestry agent, acting as an intermediary between Fonafifo and landowners and receiving a fee paid by landowners. In total, landowners support a transaction cost of $18 \%$ of the payment according to Rojas and Aylward (2003) or between $22 \%$ and $25 \%$ including other taxes, according to Baltodano (2000).

Some local non-governmental organizations (NGOs), such as Fundecor and Codeforsa, play an important role in providing technical assistance and reduce transaction costs by handling paperwork, a useful help for poorer and less educated applicants (Chomitz et al., 1999). The facilitating NGOs have been gaining experience and recognition in forestry issues by working with groups of small and medium landowners. For their facilitating role in the PSA, these NGOs receive a fee paid by landowners and representing between $12 \%$ and $18 \%$ of the payment, depending on $\mathrm{NGO}^{2}$.

Our study zone, located in the Huetar Norte conservation area, was selected because it had the highest density of reforestation under the PSA. According to Barrantes (2005), more PSA funds were assigned to reforestation in this area in 2004 than in any other area. The impacts of the PSA have already been studied in this area but with different approaches (i.e. focal group approach in Miranda et al., 2004).

This area, one of 11 administrative units defined by the Ministry of Environment, covers $7662 \mathrm{~km} 2$ ( $15 \%$ of Costa Rican territory) and is characterized by a humid tropical climate (average temperature between $25^{\circ} \mathrm{C}$ and $27^{\circ} \mathrm{C}$ and rainfall between 2500 and $4500 \mathrm{~mm}$ ). The local economy is based traditionally on agriculture (livestock and cash crops, such as ornamental plants, citrus, or pineapple) but new activities, such as ecotourism, are developing quickly. Familyrun small and medium farms and large agribusiness farms coexist in the area. According to Fonafifo, almost $60 \%$ of the area was covered by forest in 1999 , with reforestation generally established in pastures. The three most common species planted in Northern Costa Rica are Terminalia amazonia (Terminalia), Vochysia guatemalensis (Chancho), and Hieronyma alchorneoides (Pilón) (Piotto et al., 2002).

\footnotetext{
${ }^{2}$ Guillermo Navarro, CATIE, pers.comm., Sept. 2007.
} 


\subsection{Method}

The impacts on local development can be broken down into a set of principles (e.g. economic, social, human, institutional, cultural) that may in turn be broken down into criteria and indicators (Munda, 2004; Phillis and Andriantiatsaholiniaina, 2001). We applied a multi-criteria analysis integrating fuzzy set theory (Zadeh, 1965). The fuzzy set theory has been used in many research and operational areas close to the subject of this article, for example, sustainability assessment (Cornelissen et al., 2001), environmental impact evaluation (Enea and Salemi, 2001), or natural resource management (Bender and Simonovic, 2000). Fuzzy set theory enables researchers to deal with polymorphous and ambiguous concepts for which a straightforward quantification is impossible, to mathematically handle the reasoning for these concepts, and to produce concrete unambiguous answers (Phillis and Andriantiatsaholiniaina, 2001). The core of the fuzzy set theory is the concept of membership function. A fuzzy set in $X$ is characterized by a membership function $f$ that associates each point $X$ in $X$ with a real number in the interval $[0,1]$, representing the grade of membership of $x$ in the fuzzy set (Zadeh, 1965).

Our methodology included four main steps: (1) development of a set of PCI (Principles, Criteria, and Indicators), (2) fieldwork, (3) data analysis, and (4) statistical analysis. In Step 1, we developed a set of PCI to evaluate the impacts of PSA and reforestation on local development. Initially we revised and adjusted similar sets of existing PCI, e.g. by CIFOR (Prabhu et al., 1998), during two meetings with experts in rural development and forestry issues from the Tropical Agricultural Research Education Center (CATIE) in Costa Rica. ${ }^{3}$ The experts reviewed the set, adapted it to local conditions and issues, then weighted the adapted set. The weights represent the importance of each principle, criterion, or indicator for evaluating the impacts, and not the possibility of trade-off between dimensions (Munda, 2004). The five principles were assigned weights summing 100 , and then the same procedure was applied to the criteria within a principle and to the indicators within a criterion. The relative weights of each elements of the set were calculated and averaged within the group of experts (see Table 1).

\footnotetext{
${ }^{3}$ We acknowledge Andrés García, Bastiaan Louman, David Quirós, Dietmar Stoian, Fernando Carrera, Guillermo Navarro, Kees Prins, Mario Piedra, Miluzka Garay, Mónica Salazar, Octavio Galván, Sara Yalle, Vanessa Sequeira, and Zaira Ramos for their participation.
} 
Table 1 Set of principles, criteria, and indicators

Principle, criterion, or indicator (relative weight in \%)

P1. Reforestation under PSA increases landowner socioeconomic well being $(\mathbf{3 0 . 7} \%)$

C11. It increases income (17.4\%)

I111. It increases short-term income (10.2\%)

I112. It increases medium and long-term income (7.3\%)

C12. It reduces economic risk $(13.2 \%)$

I121. It increases diversification of activities (3.0\%)

I122. It increases landowner credibility when soliciting credit $(3.8 \%)$

I123. It decreases economic vulnerability because of increased assets and regular payments

$(2.8 \%)$

I124. It facilitates farm products marketing, especially forest products (3.6\%)

P2. Reforestation under PSA increases socioeconomic well being of indirect beneficiaries

$(21.2 \%)$

C21. It improves employment $(9.3 \%)$

I211. It increases the number of workers on the farm (4.3\%)

I212. It improves work conditions on the farm (2.3\%)

I213. It creates new jobs in the transportation and transformation of forest products $(2.7 \%)$

C22. It reduces the social consequences of land concentration $(5.4 \%)$

I221. It reduces land concentration (2.7\%)

I222. It reduces conflicts and forced migration due to changes in land tenure $(2.7 \%)$

C23. It improves social and economic conditions of the area $(6.4 \%)$

I231. It improves the social infrastructure in the area (3.6\%)

I232. It affects positively the other productive activities in the area $(2.8 \%)$

P3. Reforestation under PSA strengthens relationships between landowner and institutions (17.6\%)

C31. It facilitates land title legalization (8.5\%)

I311. It motivates the landowner to regularize land tenure and get titles $(4.0 \%)$

I312. It increases the protection of landowner rights (4.5\%)

C32. It improves relationships between the landowner and local or national organizations (9.1\%)

I321. It helps the landowner receive support from local or national organizations $(5.4 \%)$

I322. It reduces conflicts between beneficiary and local or national organizations $(3.7 \%)$

P4. Reforestation under PSA strengthens forestry sector institutions (17.9\% )

C41. It strengthens public forestry organizations (7.1\%)

I411. It improves public organizations assets (human capacities and physical infrastructure) $(3.9 \%)$

I412. It helps public organizations receive additional funds $(3.2 \%)$

C42. It strengthens the NGOs by increasing their usefulness $(5.1 \%)$

I421. It increases NGO services demand $(2.5 \%)$

I422. It creates incentives for NGOs to improve the quality of their services $(2.6 \%)$

C43. It facilitates law enforcement $(5.7 \%)$

I431. It forces stakeholders to respect the law (2.6\%)

I432. It facilitates law enforcement monitoring (3.1\%)

P5. Reforestation under PSA improves landowner perception on environment and forest

(12.7\%)

C51. It raises landowner awareness about forest ecosystems goods and services (6.3\%)

I511. It increases landowner satisfaction of forest ecosystems goods and services (3.3\%)

I512. It promotes landowner adoption of sustainable practices $(3.0 \%)$

C52. It incites the landowner to protect forest resources $(6.4 \%)$

I521. It incites the landowner to continue with reforestation, even without payment $(3.5 \%)$

I522. It incites the landowner to invest time and money in forest protection $(2.8 \%)$ 
During Step 2, we applied the PCI set in a field setting. First, indicators were converted into questions for guiding interviews. To evaluate the impact of the PSA, we compared the current situation with the baseline situation that would have occurred without the PSA, i.e. without reforestation or payment (in all cases, landowners declared that they would not have reforested without the PSA). We asked to landowners how their situation had changed since the beginning of the PSA and whether reported changes were due to reforestation under the PSA. For instance, the indicator about impacts on the short-term incomes was evaluated by a first question about how the landowners perceived income changes due to the reforestation and the payment during the first years of the plantation and then by secondary questions about how much money was invested, lost, and received because of PSA.

In 2004, we conducted semi-structured interviews with 37 of the 132 landowners receiving PSA for reforestation in the area (see a description of the sample in Table 2). The sampling was stratified according to farm areas and landowner main activities. Due to constraints on landowner availability and accessibility, it was not possible to reach a sampling intensity higher than $28 \%$. Other sources of information included 14 interviews with representatives of NGOs, regional offices of the Ministry of Environment, and small wood transformation industries.

Table 2 Sample description

\begin{tabular}{|c|c|c|c|}
\hline Landow ner characteristics & $\mathbf{N}$ & $\begin{array}{l}\text { Farm area in } \\
\text { hectares (mean } \\
\text { and standard } \\
\text { deviation) }\end{array}$ & $\begin{array}{l}\text { Percent of area } \\
\text { reforested (mean } \\
\text { and standard } \\
\text { deviation) }\end{array}$ \\
\hline All landowners & 37 & $93(69)$ & $52 \%(35 \%)$ \\
\hline Farmers & 9 & $105(65)$ & $55 \%(43 \%)$ \\
\hline $\begin{array}{l}\text { Working class (drivers, } \\
\text { teachers, carpenters, social } \\
\text { workers, domestic workers) }\end{array}$ & 12 & 70 (59) & $53 \%(32 \%)$ \\
\hline $\begin{array}{l}\text { Upper class (lawyers, } \\
\text { businessmen, engineers) }\end{array}$ & 8 & $76(47)$ & $51 \%(27 \%)$ \\
\hline $\begin{array}{l}\text { Agribusinesses (forest and } \\
\text { agriculture companies) }\end{array}$ & 8 & $131(94)$ & $49 \%(42 \%)$ \\
\hline
\end{tabular}

In a multi-criteria analysis, giving exact values to indicators may be difficult when indicators have not been measured quantitatively or are ambiguous (Phillis and Andriantiatsaholiniaina, 2001). Instead of assigning a single impact value, we recognized that the border between positive and negative impactswas not sharp and considered degrees of positive or negative possibility (Phillis and 
Andriantiatsaholiniaina, 2001). Moreover, problems may arise from the aggregation of the indicators into a single impact valuation. Even if stakeholders agree about weights, the aggregation approach could be a subject of dissonance due to a continuum of approaches from very conservative to very liberal. Here an example is given regarding the aggregation of two indicators, I111 "increases in short-term incomes" and I112 "increases in long-term incomes", into criterion C11 "increases in incomes". For a very conservative approach, incomes are considered to increase if both short-term and long-term incomes increase. In the general case, this means that no trade-off is allowed: only the best situations with all positive indicators would result in a positive overall evaluation. The degree $\mu$ of membership of $\mathrm{C} 11$ in the set of positive impacts is the smallest degree of membership of indicators $\mu 1$ or $\mu 2$ in the set of positive impacts. In fuzzy set theory, this operation is an intersection and is calculated by applying the minimum operator: $\mu=\min (\mu 1, \mu 2)$. For a very liberal approach, incomes are considered to increase if short-term OR long-term incomes increase. In the general case, this means that trade-off is extreme: a single positive indicator can balance the other negative indicators and result in a positive overall evaluation. This operation is a union and is calculated with the maximum operator: $\mu=\max (\mu 1, \mu 2)$ (Dubois and Prade, 1998).

Intermediate approaches may also be imagined, in which high values of some indicators may compensate low value of others (Cornelissen et al., 2001) and the degree of trade-off may vary. A parameter $\alpha$ for the degree of trade-off can vary between positive infinity for a liberal approach and negative infinity for a conservative approach. A general equation for aggregation is the following:

$$
\begin{aligned}
& \mu=\left(\frac{\mu_{1}^{\alpha}+\mu_{2}^{\alpha}}{2}\right)^{1 / \alpha} \\
& \alpha \rightarrow+\infty \quad \mu=\max \left(\mu_{1}, \mu_{2}\right) \quad \text { Maximum } \\
& \alpha=1 \quad \mu=\left(\frac{\mu_{1}+\mu_{2}}{2}\right) \quad \text { Arithmetic mean } \\
& \alpha \rightarrow 0 \quad \mu=\sqrt{\mu_{1} \cdot \mu_{2}} \quad \text { Geometric mean } \\
& \alpha=-1 \quad \mu=\frac{1 / 2}{1 / \mu_{1}+1 / \mu_{2}} \quad \text { Harmonic mean } \\
& \alpha \rightarrow+\infty \quad \mu=\min \left(\mu_{1}, \mu_{2}\right) \quad \text { Minimum }
\end{aligned}
$$

If we consider $n$ elements to be aggregated with weights ( $w_{k}$ are the weights, $k=1$ to $n$ ), the aggregation is calculated with the following equation (Grabisch et al., 1999; Cornelissen et al., 2001): 
$\mu=\left[\sum_{k=1}^{n}\left(w_{k} \cdot \mu_{k}^{\alpha}\right)\right]^{1 / \alpha}$ with $\sum_{k=1}^{n} w_{k}=1$

During Step 3, we analyzed the field data by converting each observation into a value between -1 and +1 . To avoid personal interpretations of the field data, the two authors conducted separate analyses, compared their findings, and reached consensus. With a fuzzification process, each indicator value was converted into two degrees of membership in the sets of positive and negative impacts by using sigmoid functions (see Fig. 1).

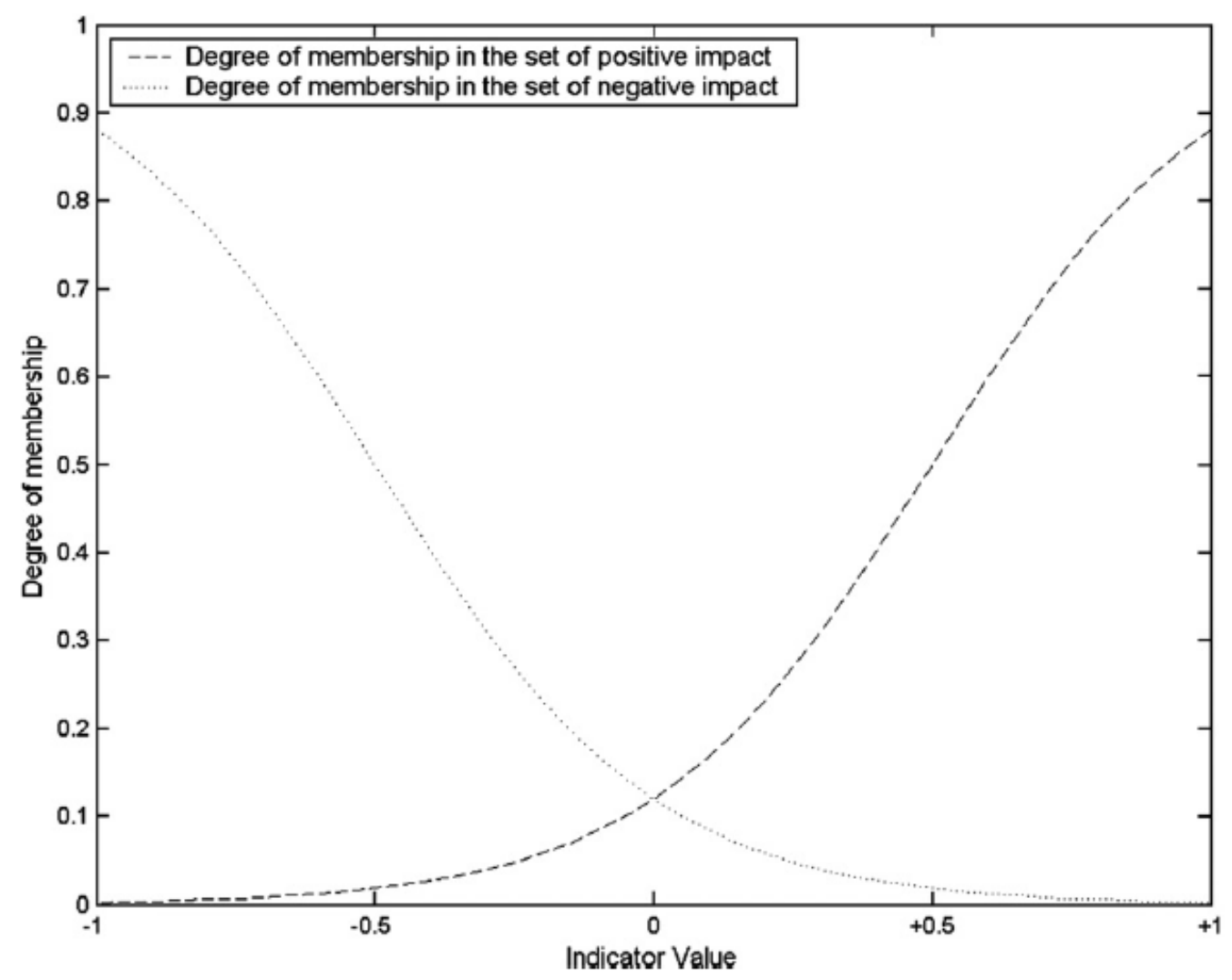

Fig. 1. Membership functions in the sets of positive and negative impacts.

Fig. 2 shows an example of fuzzy inference (Cornelissen et al., 2001) for two indicators and one criterion, in the case of a liberal approach. If the degrees of membership of I1 and I2 in the set of the positive impacts are 0.04 and 0.23 respectively, the truth-value of the premise "I1 is positive or I2 is positive" is the maximum of 0.04 and 0.23 because of the logical connective OR. As a consequence, the conclusion " $\mathrm{C}$ is positive" has a truth-value of 0.23 (graphs a to 
c). The same procedure is applied to negative impacts, utilizing the minimum operator for the logical connective AND, because the rule for negative impacts always uses the connective opposite to that of the positive rule ( $d$ to $f$ ). An overall fuzzy conclusion is drawn using the union of the two partial conclusions. A defuzzification process reaches an unambiguous impact value with the center of gravity method $(g)$.
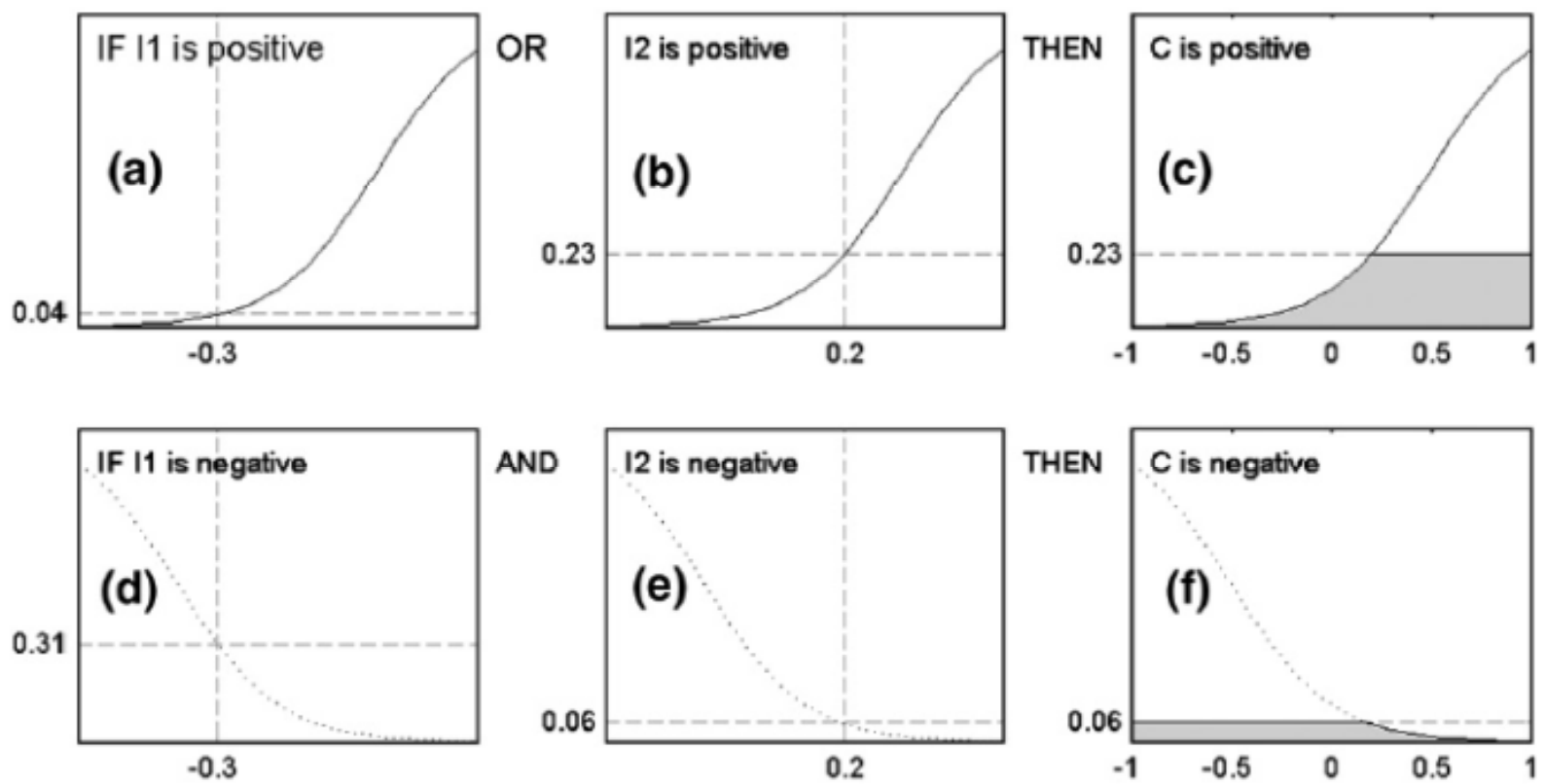

All $x$-axes show impacts

All $y$-axes show degrees of membership
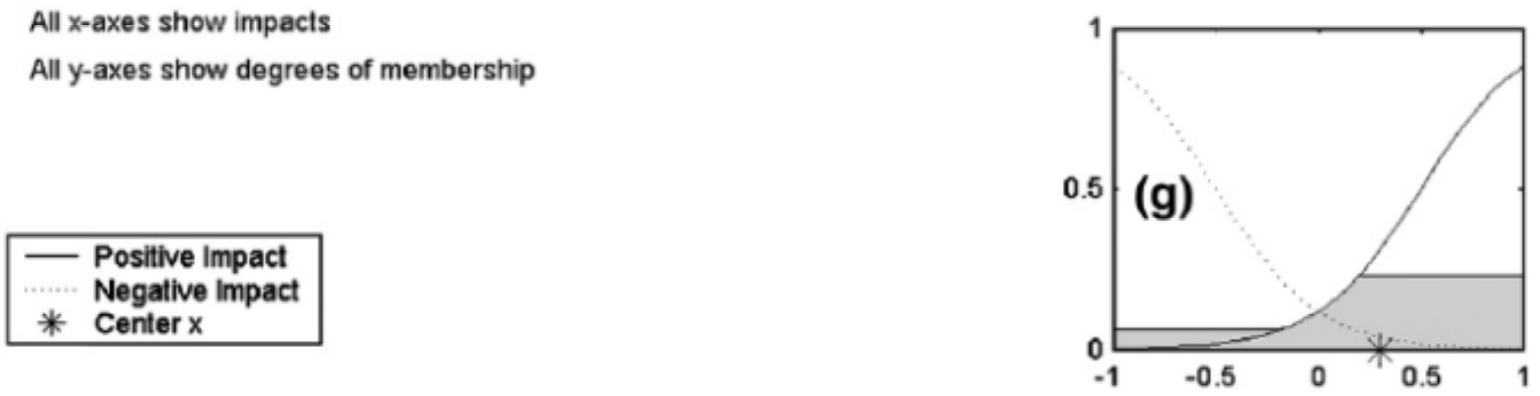

Fig. 2. Fuzzy inference and defuzzification in the case of two fuzzy rules for aggregating two indicators I1 and I2 in one criterion C.

For each landowner, the fuzzy inferences were subsequently applied for aggregating indicators into criterion, criteria into principle, and principles into overall evaluation. They were applied with seven distinct approaches from conservative to liberal. We used a linear correction so that the impact value would be +1 for a "best" landowner with all positive impacts, 0 for a "null" landowner with all null impacts, 
and -1 for a "worst" landowner with all negative impacts. All calculations were done with Matlab ${ }^{\mathrm{TM}}$.

In Step 4 statistical t-tests $(p<0.05)$ were used to assess whether the average impact for each principle or criteria was significantly different from 0 . When significant, the average impact based on the balanced approach $(\alpha=0)$ was reported qualitatively: Null (between -0.05 and 0.05 ), Moderately Negative or Positive (between 0.05 and 0.25 in absolute value), Negative or Positive (0.25$0.5)$, Very Negative or Positive (0.5-0.75), Highly Negative or Positive (0.75-1).

Using t-tests, we looked for impact differences between groups of landowners: farmers, working class, upper class, and agribusiness (see Table 2 for group description). Other comparisons were made between landowners applying to PSA through local organization $(n=16)$ and others. Some groups were defined by degrees of membership (see Fig. 3 and Table 3). When applying t-tests we considered fuzzy memberships as weights to compute weighted averages, standard deviations, and sample size.

Table 3. Fuzzy definition of landowner groups

\begin{tabular}{|c|c|}
\hline Landowner group and size & Fuzzy definition ( $\mu=$ degree of membership) \\
\hline $\begin{array}{l}\text { Small farm }(\Sigma \mu=14.74) \\
\text { Medium farm }(\Sigma \mu=9.26) \\
\text { Large farm }(\Sigma \mu=13.00)\end{array}$ & $\begin{array}{l}\text { Based on farm area (See Fig. 3) with } 40,90 \text {, and } \\
140 \text { ha as thresholds. Thresholds were based on } \\
\text { percentiles of the distribution of farm areas. }\end{array}$ \\
\hline Small farmer $(\Sigma \mu=2.82)$ & $\mu($ Small farm $)$ if landowner is a farmer \\
\hline Large farmer $(\Sigma \mu=4.23)$ & $\mu$ (Large farm) if landowner is a farmer \\
\hline $\begin{array}{l}\text { Depending on farm for } \\
\text { livelihoods }(\Sigma \mu=15)\end{array}$ & $\begin{array}{l}\mu=1 \text { : Farmers (agriculture or livestock), } \mu=0.5 \text { : } \\
\text { working class (driver, teacher, carpenter, social } \\
\text { worker, domestic worker) }\end{array}$ \\
\hline
\end{tabular}




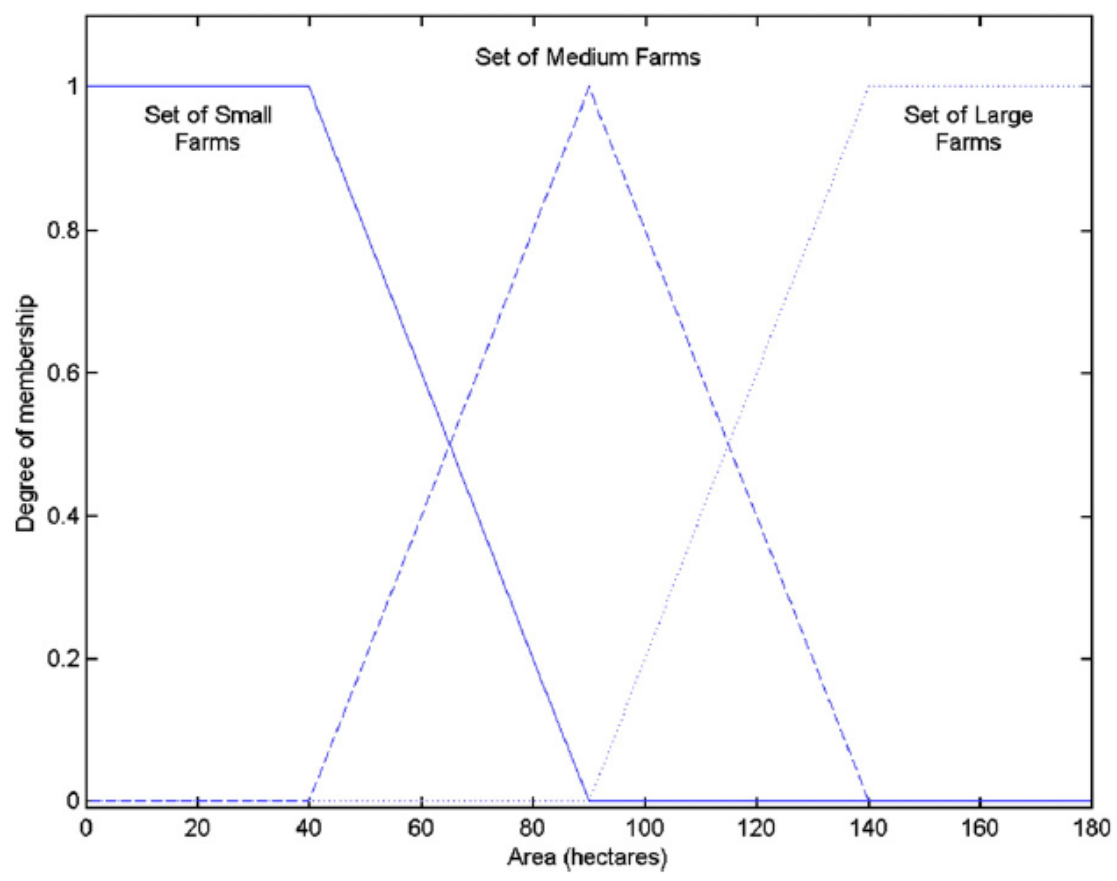

Fig. 3. Degree of membership $\mu$ in the sets of small, medium, and large farms.

Finally, to test the robustness of the conclusions, we applied a sensitivity analysis (Munda, 2004). We performed 100 calculations with all weights modified by a random factor between $-50 \%$ and $+50 \%$ and we obtained the standard deviation of the results.

\section{Results}

\subsection{Criteria and weighting}

The PCI set was organized into five principles that included 12 criteria and 27 indicators (see Table 1), covered three dimensions (socioeconomic for P1 and P2, institutional for P3 and P4, cultural for P5), and two scales (landowner for P1, P3, and P5, indirect beneficiaries for P2 and P4). The indirect beneficiaries are those affected by the PSA through employment or changes in local infrastructures and land tenure. Cultural impacts on indirect beneficiaries seemed too weak and were not included.

Economic impacts were weighted higher (31\% for P1 and $21 \%$ for P3) than institutional ( $18 \%$ for P2 and $18 \%$ for P4) or cultural impacts ( $13 \%$ for P5). The impacts on landowners were weighted higher than the impacts on indirect beneficiaries. The five criteria receiving more weight were C11 (landowner income, $17.4 \%$ of total weight), C12 (economic risk reduction for landowner, $13.2 \%$ ), C21 
(employment), C32 (landowner access to financial and technical support), and C31 (legalization of land tenure).

\subsection{I mpact valuation by different approaches}

As expected, the total impact increased from conservative to liberal approaches; the conservative approach was highly negative and the liberal approach was highly positive. Even for conservative approaches, the institutional impacts on organizations (P4) and the cultural impacts on beneficiaries (P5) were positive. For balanced approaches $(\alpha=0)$, total impact was positive and only principle P1 showed a moderately negative impact; the others were moderately to highly positive (see Fig. 4).

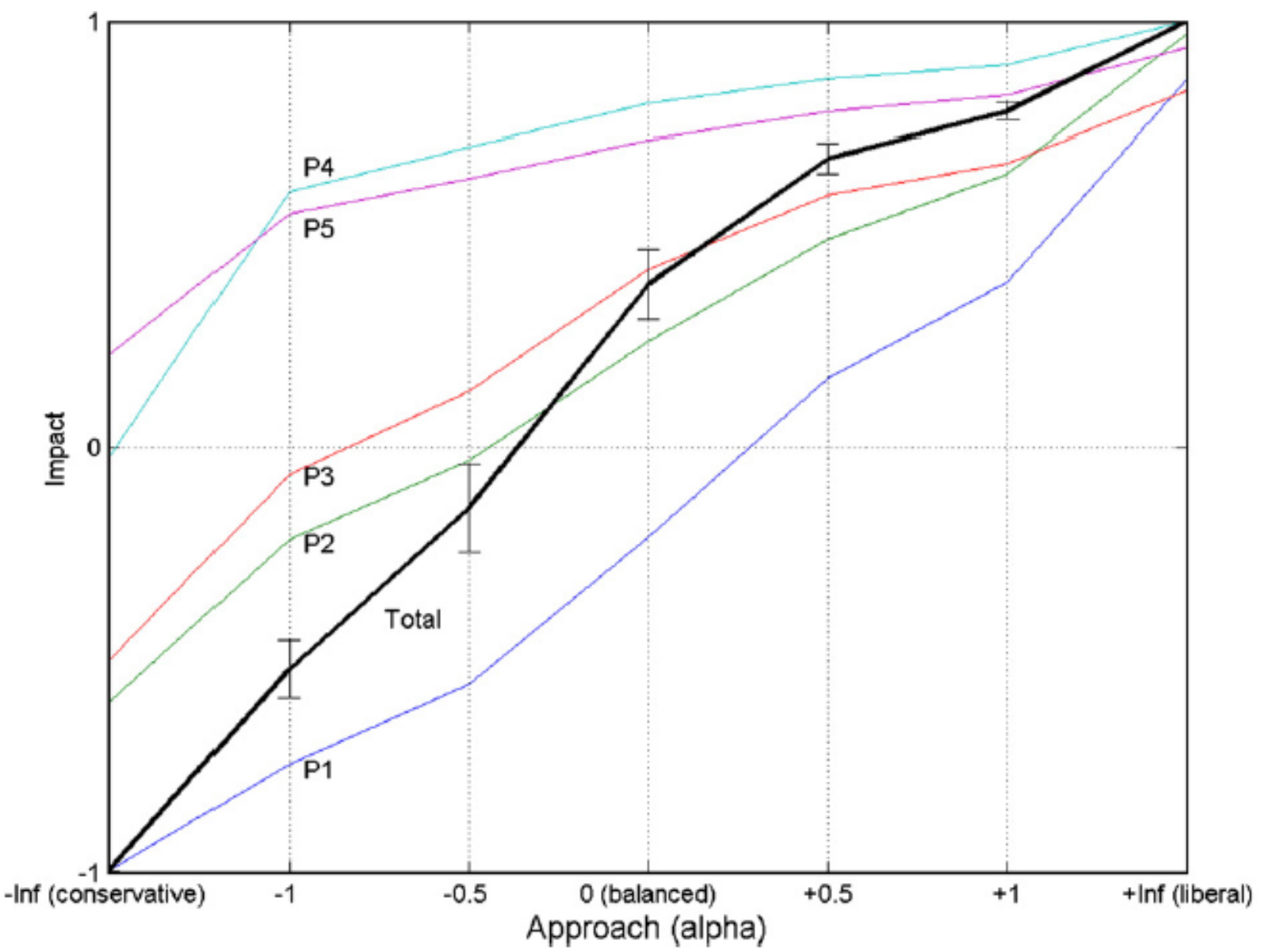

Fig.4. Impact valuation by different approaches (error bars represent the standard deviation calculated in the sensitivity analysis). 
Comparing the different approaches revealed that only five criteria always remained positive: C31 (legalization of land title), C42 (strengthening NGOs), C43 (law enforcement), C51 (landowner awareness of ecosystem services), and C52 (inciting the beneficiary to protect forest resources). Only one criterion always remained negative: C22 (social impacts of land concentration).

\subsection{Landowner's socioeconomic well being Principle}

P1 (landowner's socioeconomic well being) was the only principle with a negative evaluation by a balanced approach. The impact differed according to social class: positive for upper class and negative for three other socioeconomic classes (small farmers: negative, working class: negative, and agribusinesses: moderately negative). The two criteria $\mathrm{C} 11$ and $\mathrm{C} 12$ were not significantly different from zero because their compounding indicators reached contrasted values. Indicator I111 (impacts on short-term income) was significantly negative in the whole sample and differed between upper class (null) and working class (very negative). Even though the payment was meant to cover only part of the reforestation costs, $60 \%$ of the landowners were disappointed because the payment did not compensate costs. Indicator I112 (impact on medium and longterm income) differed between upper class (very positive) and three other groups: small farmers (very negative), working class (negative), and agribusinesses (negative). Large farmers (positive) were different from small farmers (very negative). A majority of landowners (71\%) perceived long-term reforestation to be associated with financial benefits. The remaining $29 \%$ cited uncertainties regarding wood prices and quality of future harvests.

Indicator I121 (diversification of activities) was very positive and without significant difference between landowner groups. Forty-one percent of the landowners started new activities as a consequence of reforestation under the PSA, for example small sawmills or transportation businesses. Indicator I122 (beneficiary credibility when soliciting credit) was moderately positive and higher for large farmers (positive) than for medium farmers (moderately negative). According to $38 \%$ of landowners, banks do not consider reforestation as a loan guarantee. ${ }^{4}$ Indicator I123 (decreased economic vulnerability because of increased assets and regular payments) was not significant. Seventy-one percent of landowners were satisfied with the regularity of payments, but payment and reforestation did not create a security asset. Indicator I124 (marketing) was highly negative, without discrimination between groups. No producers had sold products from the final harvest, but almost all landowners had already done a thinning. Ninety-five percent of landowners who tried to sell small-

\footnotetext{
${ }^{4}$ This information was confirmed by other informants. Another incompatibility between bank loans and the PSA was that, until very recently, Fonafifo did not accept farms with mortgages and even those that are now accepted have drastic restrictions.
} 
diameter products from thinning had trouble finding a buyer or were disappointed by prices.

\subsection{Indirect beneficiaries' socioeconomic well being}

The impact on socioeconomic well being of indirect beneficiaries (P2) was moderately positive in the whole sample and better for small farmers (positive) or employees (moderately positive) than for upper class landowners (moderately negative). The impact on employment (C21) was very positive. Within this criterion, the strongest impact was on the creation of jobs for product transportation and transformation (I213, highly positive). The impact on the number of farm workers (I211) was also positive whereas the impact on work conditions (I212) was null. Fifty-one percent of the landowners thought that reforestation, including product transportation or transformation, created additional jobs compared to livestock breeding, $16 \%$ thought the contrary, and $33 \%$ did not see any change.

The PSA has induced land concentration, considered here as a negative impact because it may bring about social disparities, conflicts, and forced migration. The impact on land concentration (C22) was stronger for upper class landowners, small farmers, and working class landowners. Although impact on land concentration was significant (I221, negative), conflicts and induced migration were insignificant (I222). Twenty-seven percent of landowners had bought more land for reforestation. Interviews with local organizations confirmed that some rich landowners or companies had bought land for reforestation.

Criterion C23 regarding impacts on area social and economic conditions was not significant, nor were the corresponding indicators I231 (social infrastructure) and I232 (other productive activities). According to the majority of landowners and organization representatives, reforestation had not induced regional changes because it is a minor activity compared to agriculture.

\subsection{Relationships between the landow ner and institutions}

The impact on the relationships between the landowner and institutions (land tenure institutions, local and national organizations) was positive (P3), especially for landowners applying to the PSA through a local NGO. Criterion C31 (land title legalization) was moderately positive and differed between small farmers (positive) and agribusinesses (null). For $92 \%$ of landowners, the PSA had no impact on legalization because they had already regularized their land titles before applying to the PSA. The same results were found for the two indicators I311 (motivation of the beneficiary to regularize land tenure and get titles) and I312 (protection of beneficiary rights). The $8 \%$ of landowners that regularized their land title with the PSA felt their rights were more protected in case of settler encroachment. 
Criterion C32 (relationships between landowners and local organizations) was positive, especially for landowners applying to the PSA through a local NGO and for small farms, for whom the impact was very positive and significantly different from other groups. The first indicator I321 (possibility of a beneficiary to request and receive support from local and national organizations) was highly positive. The vast majority ( $84 \%$ ) of landowners requested support from organizations related to the PSA at least once, and received a good response. The second indicator I322 (reduction of conflictive situations between the beneficiary and organizations) was negative. Sixty-two percent of landowners considered long-term restrictions regarding land-use change under PSA contracts a potential source of conflict with the organizations involved. Moreover, most landowners (89\%) thought another source of conflict was the too low payment.

\subsection{Forestry sector institutions}

The impact on strengthening forestry sector institutions (P4) was highly positive, especially regarding NGOs and law enforcement and to a lesser extent for public organizations. The impact was moderately positive on public forestry organizations (C41), as the PSA had not helped these organizations receive additional funds (I412, not significant), even if it had contributed to improving human capacities and physical infrastructure (I411, positive). Representatives from public forestry organizations said that the lack of budget and materials from the PSA impeded the development of capacities and better services. The impact was highly positive on NGOs (C42) and both indicators related to this criterion were highly positive. The difference between NGOs and public sector institutions is that NGOs do receive a fee from the payments, while public sector institutions do not receive additional funds to manage PSA. Stakeholders thought that the NGOs were incited to provide good services as they received a share of the PSA payment. The impact was also highly positive on law enforcement (C43) because the PSA forced stakeholders to respect the law (I431, highly positive) and facilitated law enforcement monitoring (I432, highly positive). Civil servants of the Ministry of Environment regional offices said that they monitor law enforcement when they visit PSA farms.

\subsection{Cultural impacts}

The cultural impacts were very positive (P5), without significant differences between groups. Reforestation and the PSA raised beneficiary awareness about forest ecosystems goods and services (C51, very positive), especially for farmers (highly positive). Satisfaction increased with regard to forest ecosystems goods and services (I511, very positive) and promoted the adoption of sustainable practices by the beneficiary (I512, very positive), especially for large farmers and agribusinesses. Even though most landowners had a negative feeling about the economic benefits of reforestation, $57 \%$ had a positive perception of the 
environmental benefits. Sixty-five percent of landowners had implemented measures for conserving biodiversity, ecosystems or water, after they entered in the PSA program.

The PSA and reforestation also incited the beneficiaries to protect forest resources (C52, very positive), especially for farmers and agribusinesses (very positive) compared to upper class landowners (null). The PSA motivated the beneficiaries to replant after harvesting, even without payment (I521, very positive), especially for the landowners that applied to the PSA through a local NGO. It also incited landowners to invest time and money in the protection of forest resources (I522, positive). Fifty-seven percent of landowners said they would continue with reforestation even without receiving PSA funding. The commitment of landowners to protecting forest resources (criterion C52 and its indicators) was significantly correlated with two other criteria: C12 (reduction of economic risk) and C32 (financial and technical support by organizations).

\subsection{Sensitivity analysis}

Changes in the weights hardly affected the results (see Fig. 4 where error bars represent the standard deviation of the value during 100 repetitions). For instance, the total impact value was 0.37 on average (positive impact) with a standard deviation of 0.07 ( $19 \%$ of the average). The extreme values were 0.19 (moderately positive) and 0.52 (very positive).

\section{Discussion}

The method used revealed the impact of payment for environmental services on local development, considering various dimensions (socioeconomic, institutional, and cultural) as well as distinct scales (landowner and indirect beneficiary). It is important to consider non-market benefits in evaluating impacts (Lipper and Cavatassi, 2004). Reducing the study to only the socioeconomic impacts on landowners would have drawn a negative portrait of the PSA, as one of the worst impacts was on landowners' short-term incomes and the more positive impacts were observed in the institutional and cultural aspects.

On average, the aggregated impact of the PSA was positive with a balanced evaluation approach and consistent with most studies conducted in Costa Rica (Miranda et al., 2004). The negative socioeconomic impacts on landowners seemed to be the major pitfall of the PSA for reforestation. Landowners said that the payment did not sufficiently compensate for reforestation and opportunity costs. Using secondary data from local organizations, we estimated that, in the first year, reforestation represents a further investment of $200 \mathrm{US} \$ /$ ha in addition to the PSA payment. In the following years, reforestation costs were compensated by payments. The loss of incomes due to abandonment of pasture averaged 375 
US $\$ /$ ha/year. However, this land opportunity cost varied widely due to natural and socioeconomic conditions.

Landowners without productive farm activities did not suffer loss of income when entering into the PSA. That finding explained why the impact on short-term income was null for upper class landowners and negative for small farmers, working class landowners, and agribusinesses. Many upper class landowners used their farm for recreation purposes and wanted to reforest for scenic beauty. Others wanted to build reforestation capital or start a productive activity that did not require a permanent presence. The PSA allowed these landowners to achieve their plans at lower costs.

Impacts on mid- and long-term income were negative for small farmers and the working class and very positive for upper class landowners, who may consider reforestation as an investment. Landowners with negative perceptions may lack information on income generated by plantation harvest. The negative impact may also reflect a strong preference for present incomes. Our results differed from other studies concluding on positive impacts on incomes, but dealing with the PSA applied to forest conservation (Ortiz Malavasi et al., 2003; Miranda et al., 2003). Forest conservation under PSA induces payment gains and opportunity costs (potential loss of income from wood harvesting) but impacts are often evaluated positively because opportunity costs are ignored, even though they can be higher than the payments (Wunder, 2005).

The initial investment for reforestation, as well as transaction costs and other information or skill barriers, are major hindrances to poor landowner participation. In addition, the majority of landowners were disappointed by the sale of the first thinning products, because the Costa Rican reforestation product market is not well developed. The lack of information about prices or wood quality technical specifications also reduced profits. The support of local organizations was essential as almost no farmer had experience in reforestation before starting with the PSA. An important side-impact on the socioeconomic wellbeing of landowners was the diversification of livelihoods, also reported in other countries (Grieg-Gran and Bann, 2003) and in Costa Rica, where landowners see the PSA as an opportunity to realize new economic activities, such as ecotourism or environmental education (Miranda et al., 2003).

Indirect stakeholders benefited positively from employment creation in the plantation and in the chain of value of wood products, especially with plantations by agribusinesses, which generally hired more workers than small farmers. Reforestation is labor-intensive: 1 ha of reforestation may generate 300 days of work per rotation, including the wood chain (Arias, 2004). In contrast, studies on PSA applied to forest conservation reported its impact to be neutral in terms of 
employment in marginal areas and negative in other areas (Ortiz Malavasi et al., 2003). Under forest conservation, logging-company workers or charcoal makers may lose their jobs (Wunder, 2005).

Negative impacts were observed with land concentration. Richer landowners and companies reforesting for profit were more likely to buy land and cause land concentration problems than farmers whose livelihoods depend on farm activities. Impacts on infrastructure or service provisions (e.g. roads, schools, health centers, or water supply) were not significant because reforestation is a minor activity in the area, as in other Costa Rican areas (Miranda et al., 2003).

The PSA contributed to improving relationship between landowners and institutions. Legalization of land title was only moderately improved by the PSA because most landowners already had legal titles. The PSA moderately improved land tenure security, but to a lesser extent than in other Latin American countries (Rosa et al., 2003; Wunder, 2005). The land title requisite for PSA applications is generally analyzed as positive if it promotes legalization and provides better landowner security, but it may limit the role of PSA in poverty alleviation, as many poor people do not own their lands (Wunder, 2005).

The support provided by local organizations to landowners under the PSA is another very positive impact. Contacts between landowners and local organizations facilitate capacity building and information dissemination, even regarding other businesses (Wunder, 2005). Potential conflicts between landowners and Fonafifo were identified, especially regarding the imposed land-use change restrictions, which had been misunderstood by some landowners when entering in the PSA. One landowner felt he was "trapped" by the implications of the PSA contract as he desired to transform the reforested land into another use. The payment level was also a source of discontent. However, this argument must be analyzed with caution as landowners may strategically argue in order to push for an increased payment (Echavarría et al., 2004).

The PSA contributed to strengthening the forestry sector institutions (P4). Other studies found that institutional innovation and de-bureaucratization were necessary for developing and implementing the PSA (Miranda et al., 2003). Some NGOs benefited from wide recognition in Costa Rica and abroad for their contributions to the implementation of the innovative PSA mechanism.

The PSA also increased law enforcement by facilitating monitoring and improving landowner awareness. The PSA had very positive impacts on landowner perceptions of environment or forest and incited forest protection. It was difficult to distinguish the impacts of the PSA from the effects of Costa Rican environmental education programs. However, changes in the perceptions of reforestation are probably due to the PSA because the landowners had not reforested prior to the PSA. Local 
organizations played an important role in providing information and organizing capacity building for landowners. In other locations throughout Costa Rica, the PSA provided training sessions, environmental education, and new forest and farm management knowledge (Miranda et al., 2003).

\section{Conclusion}

Our evaluation of the PSA applied to reforestation is globally positive; the negative economic impacts are balanced by the positive institutional and cultural impacts.

The impact on local development depends on the composition of the set of beneficiaries (Pagiola et al., 2005). In other places in Costa Rica, for instance in the Virilla watershed (Miranda et al., 2003), the large majority of landowners receiving PSA are upper class and do not depend on the farm for their livelihoods. In our sample, the impacts of the PSA on the poorest landowners (small farmers and working class landowners) were notably positive in most dimensions, except regarding income. On the contrary, the impacts were often null for upper class landowners and in some cases, such as land concentration, negative.

The best option for enhancing local development impacts would be to focus the PSA on the poorest landowners. However, the major problem is that the incomes of the poorest landowners, especially their short-term incomes, decreased as a consequence of reforestation. This problem may engender negative outcomes and reduce the participation of the poorest landowners. Proactive effortsmust bemade to ease the participation of less educated and poorer applicants for the PSA to be used as an instrument of poverty reduction. To improve income impacts, additional support could be provided to the poorest landowners when reforesting under the PSA. This could be done through additional financial incentives, such as advance payments for wood purchase, implemented by Fundecor in Costa Rica.

The strongest positive impacts were for landowners applying to the PSA through a local NGO. These organizations provided services to the landowners beyond the payment that partly explain the positive impact. The organizations also reduced transaction costs and paperwork, so that less educated and poor landowners could participate in the PSA. However, this positive impact cannot necessarily be generalized to other cases because of the specificities of two local organizations in Central and Northern Costa Rica (Fundecor and Codeforsa). They are locally and internationally well-known and respected for their capacity to adapt to changing legal and economic conditions, to generate new technical knowledge, and to create innovative approaches for protecting or enhancing forest resources (Camacho et al., 2002). Many positive aspects of the PSA applied to reforestation are due to the productive nature of activities. Compared to payment for forest conservation or other economically reducing activities, the impacts of reforestation on employment 
and long-term income are better (Pagiola et al., 2005). The impacts on incomes depend on the existence of timber markets and the capacity of landowners to negotiate prices. As incentives to reforestation prior to the PSA ended in failure because of a lack of markets for timber, special attention should be given to marketing issues.

The PES programs applied to reforestation are not a panacea for local development problems but they may have positive impacts on various dimensions of sustainable development. They may promote the introduction of trees in the landscapes and provide goods and services for local communities. They may also provide more environmental awareness in the population, more diversification of the local economy, and stronger institutions. For impacts to be positive, the PES programs should involve and support small landowners. However, this may increase the complexity of PES programs, raise transaction costs, and reduce the total supply of environmental services. As mentioned by other authors (Kosoy et al., 2007), a trade-off must be found between the environmental and social goals in PES programs.

\section{Acknowledgements}

We acknowledge with gratitude the valuable help of the landowners and representatives of Fundecor, Minae, Fonafifo, and Codeforsa. We thank Guillermo Navarro, Cornelius Prins, Zenia Salinas, and Dietmar Stoain for their comments. This work was supported by the Finnish Department for International Development Cooperation (Finnida).

\section{References}

Arias, G., 2004. Análisis del impacto económico y social de las plantaciones forestales en Costa Rica. Fundación para el desarrollo de la Cordillera Volcánica Central (Fundecor), San José. 25 p.

Baltodano, J., 2000. Pagos por servicios ambientales para la reconstrucción ecosistémica, fortalecimiento de organizaciones locales y desarrollo rural. Ciencias Ambientales (Costa Rica) 18, 21-30.

Barrantes, A.R., 2005. Programa de Pago por Servicios Ambientales (PSA): su evolución entre 1997 y 2004. Oficina Nacional Forestal, San José, Costa Rica.

Bender, M.J., Simonovic, S.P., 2000. A fuzzy compromise approach to water resource systems planning under uncertainty. Fuzzy Sets and Systems 115, 35-44.

Bull, G.Q., Bazett, M., Schwab, O., Nilsson, S., Whited, A., Maginnis, S., 2006. Industrial forest plantation subsidies: impacts and implications. Forest Policy and Economics 9, 13-31. 
Camacho, M.A., Segura, O., Reyes, V., Miranda, M., 2002. Gestión local y participación en torno al pago por servicios ambientales: Estudios de caso en Costa Rica. El Salvador, Prisma Foundation, Report for the project Pago por Servicios Ambientales en Las Américas, 116 pp.

Chomitz, K.M., Brenes, E., Constantino, L., 1999. Financing environmental services: the Costa Rican experience and its implications. The Science of the Total Environment 240, 157-169.

Cornelissen, A.M.G., van den Berg, J., Koops,W.J., Grossman,M., Udoa, H.M.J., 2001. Assessment of the contribution of sustainability indicators to sustainable development: a novel approach using fuzzy set theory. Agriculture, Ecosystems and Environment 86, 173-185.

de Groot, R.S., Wilson, M.A., Boumans, R.M.J., 2002. A typology for the classification, description and valuation of ecosystem functions, goods and services. Ecological Economics 41, 393-408.

Dubois, D., Prade, H., 1998. An introduction to fuzzy systems. Clinica Chimica Acta 270, 3-29.

Echavarría, M., Vogel, J., Albán, M., Meneses, F., 2004. The impacts of payments for watershed services in Ecuador: emerging lessons from Pimampiro and Cuenca. Markets for Environmental Services Series, $n^{\circ} 4$. International Institute for Environment and Development, London.

Enea, M., Salemi, G., 2001. Fuzzy approach to the environmental impact evaluation. Ecological Modelling 135, 131-147.

Fonafifo, 2006. Environmental Services Statistics. Fondo Nacional de Financiamiento Nacional, San José, Costa Rica. Webpage http://www. fonafifo.com visited on December 2006.

Grabisch, M., Orlovski, S.A., Yager, R.R., 1999. Fuzzy aggregation of numerical preferences. In: Slowinski, Roman (Ed.), Fuzzy Sets in Decision Analysis, Operations Research and Statistics. Handbooks Of Fuzzy Sets Series, vol. 1. Kluwer Academic Publishers, pp. 31-68.

Grieg-Gran, M., Bann, C., 2003. A closer look at payments and markets for environmental services. In: Gutman, P. (Ed.), From Goodwill to Payments for Environmental Services: A Survey of Financing Options for Sustainable Natural Resource Management in Developing Countries. WWF, Washington DC, pp. 27-40. 
Grieg-Gran, M., Porras, I.T.,Wunder, S., 2005. How can market mechanisms for forest environmental services help the poor? Preliminary lessons from Latin America. World Development 33 (9), 1511-1527.

Kosoy, N., Martinez-Tuna, M., Muradian, R., Martinez-Alier, J., 2007. Payments for environmental services in watersheds: Insights from a comparative study of three cases in Central America. Ecological Economics 61 (2-3), 446-455.

Lipper, L., Cavatassi, R., 2004. Land-use change, carbon sequestration and poverty alleviation. Environmental Management 33 (S1), S374-S387.

Miranda, M., Porras, I.T., Moreno, M.L., 2003. The social impacts of payments for environmental services in Costa Rica. Markets for Environmental Services Series, $n^{\circ}$ 1. International Institute for Environment and Development, London.

Miranda, M., Porras, I.T., Moreno, M.L., 2004. The social impacts of carbon markets in Costa Rica. A case study of the Huetar Norte region. Markets for Environmental Services Series, $n^{\circ}$ 6. International Institute for Environment and Development, London.

Munda, G., 2004. Social multi-criteria evaluation: methodological foundations and operational consequences. European Journal of Operational Research 158, 662677.

Ortiz Malavasi, E., Sage Mora, L.F., Borge Carvajal, C., 2003. Impacto del programa de pago de servicios ambientales en Costa Rica como medio de reducción de la pobreza en los medios rurales. Unidad Regional de Asistencia Técnica (RUTA), Documento de trabajo ${ }^{\circ} 8$. San José, Costa Rica.

Pagiola, S., Arcenas, A., Platais, G., 2005. Can payments for environmental services help reduce poverty? An exploration of the issues and the evidence to date. World Development 33 (2), 237-253.

Perez, C., Roncoli, C., Neely, C., Steiner, J.L., 2007. Can carbon sequestration markets benefit low-income producers. Agricultural Systems 94 (1), 2-12.

Phillis, Y.A., Andriantiatsaholiniaina, L.A., 2001. Sustainability: an ill-defined concept and its assessment using fuzzy logic. Ecological Economics 37, 435-456.

Piotto, D., Montagnini, F., Kanninen, M., Ugalde, L., Víquez, E., 2002. Plantaciones forestales en Costa Rica y Nicaragua: comportamiento de las especies y preferencias de los productores. Revista Forestal Centroamericana 38, 59-66.

Prabhu, R., Colfer, C.J.P., Dudley, R., 1998. Guidelines for developing, testing and selecting criteria and Indicators for sustainable forest management. Center for 
International Forestry Research (CIFOR). http://www.cifor.cgiar. org/acm/pub/toolbox.html.

Rojas, M., Aylward, B., 2003. What are we learning from experiences with markets for environmental services in Costa Rica? A review and critique of the literature. Markets for Environmental Services Series, $n^{\circ} 2$. International Institute for Environment and Development, London.

Rosa, H., Kandel, S., Dimas, L., 2003. Compensation for Environmental Services and Rural Communities. PRISMA, San Salvador.

Rosales, R.M.P., 2003. Developing pro-poor markets for environmental services in the Philippines. Markets for Environmental Services Series, $n^{\circ} 3$. International Institute for Environment and Development, London.

Sell, J., Koellner, T., Weber, O., Pedroni, L., Scholz, R.W., 2006. Decision criteria of European and Latin American market actors for tropical forestry projects providing environmental services. Ecological Economics 58, 17-36.

Smith, J., Scherr, S.J., 2003. Capturing the value of forest carbon for local livelihoods. World Development 31 (12), 2143-2160.

Totten, M., Pandya, S.I., Janson-Smith, T., 2003. Biodiversity, climate, and the Kyoto Protocol: risks and opportunities. Front Ecol Environ 1 (5), 262-270.

Tschakert, P., 2007. Environmental Services and Poverty Reduction: Options for Smallholders in the Sahel, Agricultural Systems 94 (1), 75-86.

Vogel, J., 2002. Markets or Metaphors? A Sustainable Livelihoods Approach to the Management of Environmental Services: Two Cases from Ecuador. International Institute for Environment and Development, London, UK.

Wunder, S., 2005. Payments for Environmental Services: Some Nuts and Bolts. Center for International Forestry Research CIFOR, Indonesia.

Zadeh, L.A., 1965. Fuzzy sets. Information and Control 8, 338-353.

Zbinden, S., Lee, D.R., 2005. Paying for environmental services: an analysis of participation in Costa Rica's PSA program. World Development 33 (2), 255-272. 